\title{
Late Holocene Paleoclimate and Paleogeography in the Tien Shan- Balkhash Region
}

\author{
B. J. Aubekerov, R. Sala, S. A. Nigmatova \\ Laboratory of Geo-Archaeology, Institute of Geology, Academy of Sciences, Almaty, Kazakhstan; ispkz@nursat.kz
}

The Tien Shan-Balkhash region (Semirechie) (Fig. 1) is a rich natural archive of paleoclimatic data but is poorly known. Research in this region, performed during Soviet times and resumed in recent years, shows that changes in atmospheric circulation, paleoclimate, and paleo-geographical conditions, including a chronology of basic events in the arid continental regions of Central Asia, can be successfully reconstructed. Research included multiproxy reconstruction from geological-geomorphological, hydrological, paleontological (paleobotanical, palinological), pedological (micromorphological) and archeological studies, as well as independent dating methods (EPR - Electronic Paramagnetic Resonance; ${ }^{14} \mathrm{C}$ ).

\section{Quaternary Climatic Events}

Data collected during Soviet times concerning the Quaternary period as a whole, are based on qualitative analyses and relative dating, and provide low temporal resolution. The following results have been reported:

- The formation of the highmountain range of the Tien Shan began during the Pleistocene, 1.6-1.3 million years BP.The rise of plateaus above $3000 \mathrm{~m}$ and the establishment of the first and largest glaciation occurred 1.2-1.1 million yrs BP.

- In the second half of the Pleistocene (0.5 million yrs BP), the increase in mountain height to more than $5000 \mathrm{~m}$ blocked the path of the Indian monsoons. This caused a reduction and then total halt of monsoonal influence on West-Central Asia and started the process of aridization that gave the region its modern features.

- With the fading of the monsoonal influence, polar air masses from the Arctic glacial zone (Siberian anticyclone) and eastward branches (along $45^{\circ}-50^{\circ}$ latitude) of the Atlantic anticyclone (Azores High) began to play a major role. In this way, the

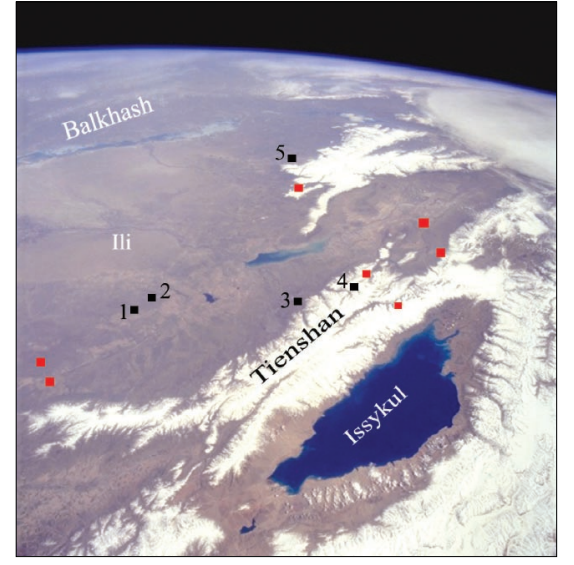

Figure 1: Satellite image STS059-223-042, April 1994. Issyk-kul Lake, Northern Tien Shan and, $400 \mathrm{~km}$ north, the Balkhash Lake partly iced. In the upper right, the atmospheric circulation patterns of the Siberian anticyclone are visible. Black dots indicate sites for palinological and geo-archeological research: 1-Tamgaly (800 $\mathrm{m}$ asl) and 2-Serektas (750 m) in semidesert landscape of the Chu-lli range; 3-Talgar $(800 \mathrm{~m})$ in piedmont steppes and 4 Turghen $(1800 \mathrm{~m})$ in mountain meadows of Northern Tien Shan; 5-Tasbas $(1600 \mathrm{~m})$ in middle mountain steppes on the northern slopes of the Jungarian range. Red dots indicate sites of geo-archaeological research: from left to right Kuljabasi, Oi-Jailau, Assy, Saty, Charyn, Usunbulak, and Koksu.

modern mode of atmospheric circulation was established.

Throughout the Quaternary Period, latitudinal changes in the positioning of the Atlantic anticyclone and its branches exerted a crucial influence on the climate of Kazakhstan and Semirechie. It characterized the switch between glacial and interglacial periods and, during interglacial and Holocene times, between pluvial and arid phases. Changes in the position of the Atlantic anticyclone also affected the water balance of interior reservoirs (Caspian, Aral, Balkhash, Alakol, Zaisan) and the volume of ice deposits in theTien Shan Mountains. Thus, lakes and mountains provide complementary archives for paleoclimatic reconstruction. In Semirechie during the Holocene period, we reconstruct regular alternation between arid (hot-dry) and pluvial (cold-wet) phases, correlated with high (northerly) and low (southerly) positioning of the Atlantic anticyclone.

\section{Late Holocene Climate and Human Adaptation}

Quantitative evaluation and absolute dating of paleoclimatic changes for the late Holocene have only been attempted in the last 5 years in the context of geo-archeological research for project INTAS 97-2220. Temperature and precipitation reconstructions are based on palinological data and transfer functions located in three different zones: The semideserts of Southern Pre-Balkhash, the foothills of the Tien Shan and Jungarian ranges, and the high mountains. Sites with average trench depths of $250 \mathrm{~cm}$ provided a 3000-3500 year sequence of events. Samples were collected every 7-15 cm to allow 150year temporal resolution. Dating was based on EPR of carbonates and on correlation with archeological findings from settlements and tombs submitted for ${ }^{14} \mathrm{C}$ analyses.

It has been established that local climatic fluctuations are well correlated in tendency, time and periodicity with global estimates. But relevant regional anomalies, mainly determined by the continental location of the region, are also observed (phase 3), emphasizing the forcing impact of seasonal anomalies. Also, sub-regional differences exist between plains and mountains because of their different exposure to drought and glacial events and the different (sometimes opposite) reaction of their environments to climatic variations.

In Semirechie, climatic forcing on borders of landscape zones in plains, and of vertical belts in mountains is strong enough to influence human use of large areas. In such cases, one can analyze both the correlation between climatic and palinological events, as well as patterns of human land-use and environmental adaptations such as settlement localization, switches between sedentary and nomadic life or between pastoralist and farming activities, or development of irrigation schemes, etc. 


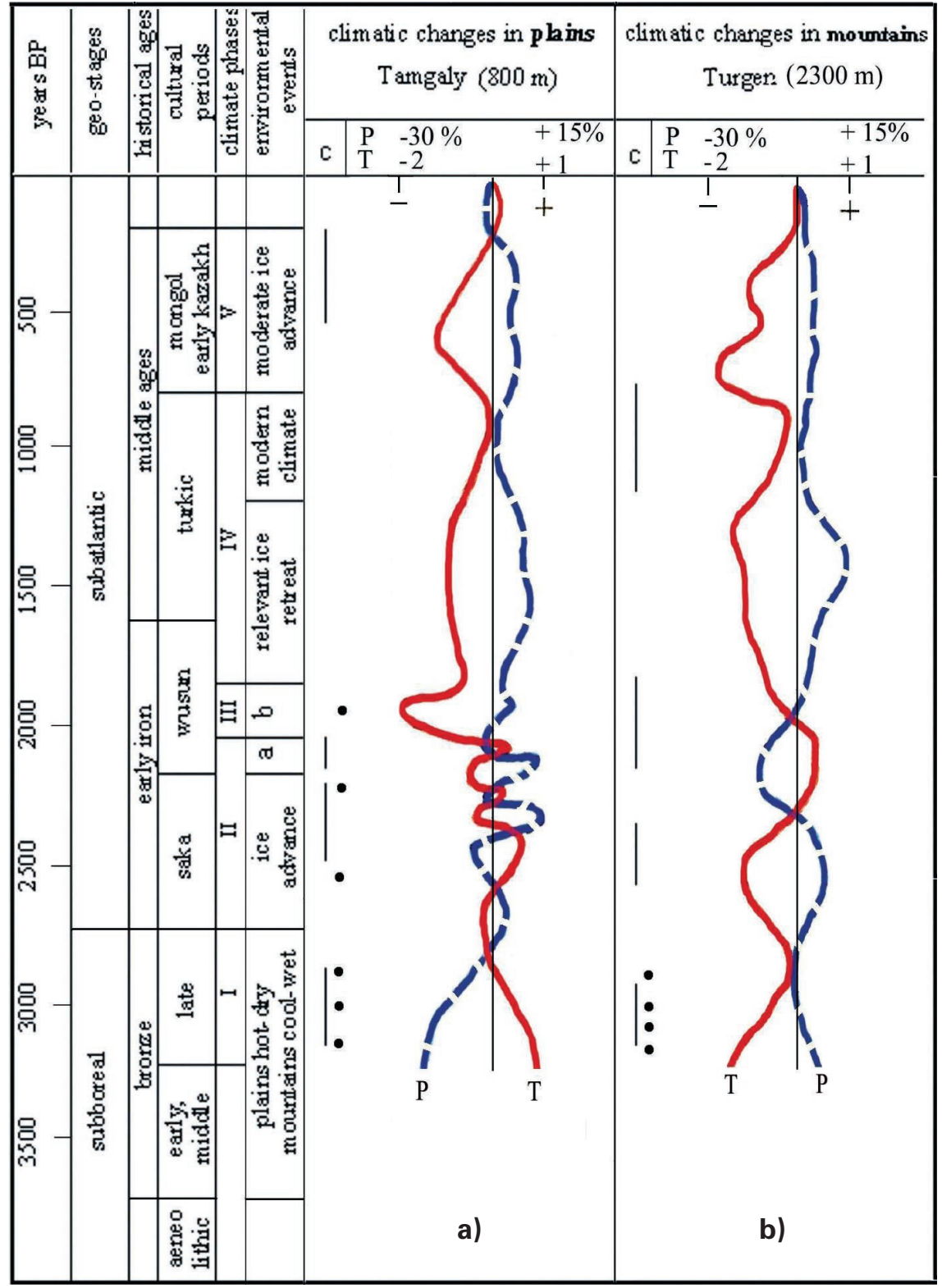

Figure 2: Reconstruction of average temperature and precipitation in Semirechie during the last 3200 yrs (150 yrs temporal resolution; based on palinological analyses). a) In plains (Tamgaly, $800 \mathrm{~m}$ asl, semidesert landscape); b) In mountains of Semirechie (Turghen, $2300 \mathrm{~m}$ asl, alpine meadows). Temperature ( $T$ ) is indicated by red lines, precipitation $(P)$ by blue dashed lines. The absolute chronology is provided by EPR and ${ }^{14} \mathrm{C}$ analyses (dots) and archaeological correlation (segments).

Modern climatic conditions in Semirechie including the arid continental plains and humid mountains are moderately hot and dry, with an average continentality index of 30. Preliminary reconstruction of paleoclimate and human land-use in plain and mountain zones of Semirechie during the last 3200 years distinguishes 5 main phases, described below (Fig. 2).

Calibration with modern standards suggests that during the whole interval, average temperature range fluctuated between $+1^{\circ} \mathrm{C} /$ $-2^{\circ} \mathrm{C}$; precipitation between $\pm 20 \%$ in plains and $\pm 30 \%$ in mountains, and continentality indexes between 27 and 34 . The five main phases are as follows:

\section{Late Subboreal: Late-Final Bronze Age (3200-2800 BP)}

Plains had arid conditions, slightly warmer and drier than modern; mountains had humid conditions, slightly cooler and wetter than modern. Glaciers on the Northern Tien Shan contracted to less than 2 $\mathrm{km}$ in length. Balkhash water level continued to shrink (from $344 \mathrm{~m}$ asl at $3800 \mathrm{BP}$ ) to less than $342 \mathrm{~m}$ asl. From this time on it fluctuated around the $342 \mathrm{~m}$ level, due to a complex balancing of synchronic hydrological changes and the melt- ing of former accumulations of ice. The borders of vegetative cover in all landscape zones and vertical belts remained close to modern. Human communities (Late Bronze culture) practiced pastoralist activities with settled villages in mountain habitats (Assy $2500 \mathrm{~m}$ asl, Turghen $2300 \mathrm{~m}$, Tasbas 1600 m, Oi-Jailau 1400) and scattered houses in oases of piedmonts and plains (Tamgaly $800 \mathrm{~m}$ ).

\section{Early Subatlantic; Early Iron Age (2800-2000 BP)}

The average climate was pluvialcooler and wetter than modern, with larger seasonal amplitudes of temperature and humidity. Both plains and mountains had cold-wet conditions, with some differences in periodicity: In plains the peak of cold and humidity fell around $2400 \mathrm{BP}$; in the mountains around $2200 \mathrm{BP}$, a difference probably due to prolonged ice accumulation. Glaciers on the Northern Tien Shan grew back to more than $2 \mathrm{~km}$ in length. Balkhash water levels reached a minimum of $338 \mathrm{~m}$ around $2500 \mathrm{BP}$ and then peaked at a maximum of $343 \mathrm{~m}$ in 2200 BP.The borders of vegetal zones in the plains and mountains changed in response to climatic fluctuations. Alpine zones became glacial and were abandoned (at least during the cold season). Semidesert plains were transformed into steppes, consistently increasing the potential areas of human activity and favoring the conversion to nomadic pastoralism with seasonal occupation, new herd composition, horse riding, demographic expansion, and relative decline in stable housing mostly located in the piedmont zone halfway between winter and summer pastures. A major economical and cultural change occurred (Saka and early Wusun cultures).

\section{Short Interval 2000-1800 BP}

This period must be noted for its peculiarity. There are ubiquitous signs of increased continentality, with very severe cold-dry winters and cold-wet summers. The phenomenon is most pronounced in plains where exceptionally cold temperatures and seasonal contrasts of precipitation caused a botanical catastrophe and 
cryolitic formations. Data suggest the establishment of an exceptional blockage of winter atmospheric circulation in Central Asia for almost two centuries, which must correspond to some climatic events of global dimension. Steppes were reduced and human habits become more sedentary, with primitive agricultural practices in the piedmont fans (Wusun culture).

\section{Middle Subatlantic; Early and Mid Middle Ages (1800-800 BP)}

Plains and mountains were characterized by cold-wet conditions until 1000 BP when conditions close to modern were established. Continentality indexes remained high with cold-dry winters. The Northern Tien Shan saw a catastrophic degradation of ice deposits from which they never recovered. Balkhash water levels decreased to a minimum of 339 $m$ around 800 BP. Human geography saw the expansion of agricultural activities together with the spread of irrigation practices, proto-urbanization along river courses and the blossoming of the northern branch of the Silk Road (late Wusun and Turkic periods).

\section{Late Subatlantic; Middle and Late Middle Ages (800-200 BP)}

Climate became cooler and wetter than either the former period or the modern climate. Moderate advances of ice occurred. The plains reached a minimum temperature around $550 \mathrm{BP}$, the mountains around 250 BP. Balkhash water levels continued to rise until a peak of $344 \mathrm{~m}$ was reached in $1910 \mathrm{AD}$. A conversion to pastoralist practices and nomadic habits took place. Most likely this was favored by the reestablishment of climatic conditions similar to those of the Early Iron Period but also by political military events and the crisis in the Silk Road trade (Mongol and early Kazakh periods). After 200 BP, climatic conditions tended progressively towards the warmer and drier conditions of modern times.

\section{REFERENCES}

Aubekerov B.J., 1993: Stratigraphy and paleogeography of the plain zones of Kazakhstan during the late pleistocene and holocene. In: Development of landscape and climate of Northern Asia, late pleistocene and holocene. Vol 1, pp101-110. Nauka, Moscow (in Russian).

Aubekerov B.J., Sala R., Nigmatova S. and Shakupova S., 2001: Paleoclimatic conditions in the arid zones of Semirechie during the Bronze and Early Iron epochs. In: Natural and social problems of geography of arid regions, pp 26-33. KAZNY, Almaty (in Russian).

Kremenezki K.B. and Tarasov P.E., 1994: Paleogeographic study of Kazakhstan during the holocene: palinology and stratigraphy. Nauka, pp151-159. Moscow (in Russian).

Pakomov M.M. and Chupina L.H., 1973: The general formation laws of the modern spore-pollen spectra in the eastern mountains of Central Asia. In: Trudi, Mesdunarodnie Palinologiskaya Conferentsia. Moscow (in Russian).

Tarasov P.E. et. Al., 1992: Climatic fluctuation in the steppe zone of Kazakhstan during holocene, based on data from spore-pollen analyses. Vestnik MGU series 5, Geography n 1-94, pp 99-103. Moscow (in Russian).

\title{
Holocene Ocean-Climate Variations in the Gulf of California, Mexico
}

\author{
Robert Douglas ${ }^{1}$, Oscar Gonzalez-Yajimovich ${ }^{1,2}$, Donn Gorsline ${ }^{1}$, Francisca Staines-Urias ${ }^{1,2}$ and J. Fernando Arreola-Hernandez ${ }^{1,3}$ \\ ${ }^{1}$ Department of Earth Sciences, University of Southern California, Los Angeles, California 90089-0740, USA; rdouglas@usc.edu; \\ 2 Facultad de Ciencias Marinas, Universidad Autonoma de Baja California, Ensenada, Mexico; \\ ${ }^{3}$ Centro Interdisciplinario de Ciencias Marinas-Instituto Politecnico Nacional, La Paz, Mexico.
}

Despite complexities, the Gulf of California can be considered an ocean-climate system in which primary productivity and sedimentation are largely controlled by seasonal monsoon winds. It offers an ideal model for exploring the oceanclimate variations in which decadal to millennial scale changes can be reconstructed from sediment cores that sample the latest Pleistocene and Holocene.

During winter months, strong NW winds flow down the length of the Gulf, cooling surface waters, and initiating surface mixing and Ekman transport along the eastern margin and the development of a major winter-spring bloom of diatoms. Primary productivity rates in the central Gulf can exceed $4 \mathrm{gC} / \mathrm{m}^{2} /$ day during the winter season, making the Gulf one of the more productive sites in the global ocean. The winds also transport large quantities of dust, which together with the flux

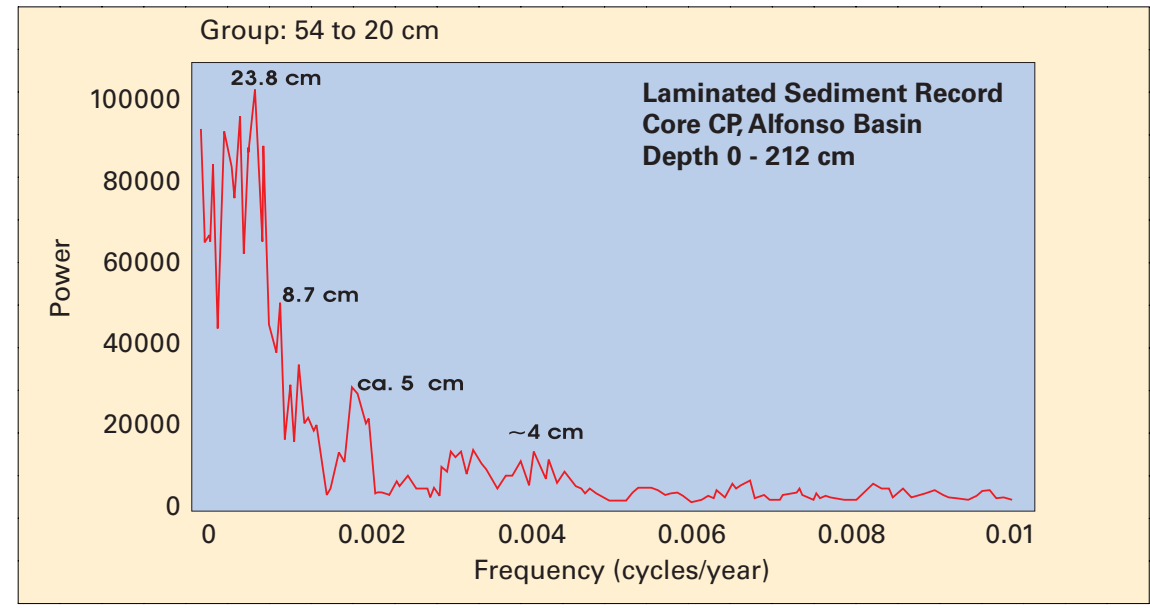

Figure 1: Spectra of peaks of variability found in laminated sediments and carbonate content in core BAP96-CP, Alfonso Basin (MTM method). Major periodicities are given in Table 1.

of biogenic debris contribute to the clayey mud that predominates in slope and basin sediments.

During summer months, winds are from the SE, a strong thermocline develops, which reduces nutrient transfer and there is a decline in primary productivity. The biogenic flux to the seafloor is dominated by pelagic carbonate and so-called "shade floras", matforming and large centric diatoms which grow in the nutricline. The mats are dumped to the seafloor in late autumn or early winter with the onset of the NW winds. In the central and eastern Gulf, these matforming diatoms contribute to the formation of sediment laminations. The SE winds bring summer storms 